\title{
A Septal-Hypothalamic Pathway Drives Orexin Neurons, Which Is Necessary for Conditioned Cocaine Preference
}

\author{
Gregory C. Sartor and Gary S. Aston-Jones \\ Department of Neurosciences, Medical University of South Carolina, Charleston, South Carolina 29425
}

Orexins (also called hypocretins) have been shown to be importantly involved in reward and addiction, but little is known about the circuitry that regulates orexin neuronal activity during drug-seeking behaviors. Here, we examined inputs to the lateral hypothalamus (LH) orexin cell field from the lateral septum (LS) using tract-tracing and Fos immunohistochemistry after cocaine (10 mg/kg) conditioned place preference (CPP) in Sprague Dawley rats. We found that neurons in rostral LS (LSr) that project to LH are Fos-activated in proportion to cocaine CPP, and that inhibition of LSr neurons with local baclofen and muscimol microinjection $(0.3 / 0.03 \mathrm{nmol})$ blocks expression of Fos in LH orexin cells and cocaine preference. In addition, using local inactivation in LS and orexin antisense morpholinos in LH, we found that LSr influences on LH orexin neurons are critical for the expression of cocaine preference. These results indicate that LSr activates LH orexin neurons during cocaine place preference, and that this circuit is essential for expression of cocaine place preference.

\section{Introduction}

Orexins A and B (also called hypocretins A and B) are neuropeptides produced exclusively in hypothalamus (Sakurai et al., 1998). Orexin neurons project throughout the neuraxis (Peyron et al., 1998), and signal via two receptors: OX1R and OX2R (Sakurai et al., 1998). Soon after the discovery of orexins, studies in humans and animals revealed that disruptions in this hypothalamic peptide system produced narcolepsy-like symptoms (Chemelli et al., 1999; Lin et al., 1999; Nishino et al., 2000), indicating a role in arousal (Sutcliffe and de Lecea, 2002).

Results from our laboratory and others reveal that orexins are also critically involved in drug abuse and other reward behaviors (Boutrel et al., 2005; Harris et al., 2005; Borgland et al., 2009; Moorman and Aston-Jones, 2009; Smith et al., 2009, 2010). Based on a variety of experiments, our laboratory proposed that the orexin system is functionally dichotomous, such that lateral hypothalamus ( $\mathrm{LH})$ orexin neurons are involved in reward and drug abuse behaviors, but perifornical (PFA) and dorsomedial (DMH) orexin neurons are involved in stress and arousal functions (Harris and Aston-Jones, 2006). Additional studies revealed that the orexin system is involved in several addiction-related behaviors (Boutrel et al., 2005; Harris et al., 2005; Smith et al., 2009, 2010; Sharf et al., 2010; Hutcheson et al., 2011). Together, these and other related studies make it a strong candidate as a potential pharmacological target in the treatment of addiction.

Received Sept. 6, 2011; revised Jan. 27, 2012; accepted Feb. 2, 2012.

Author contributions: G.C.S. and G.S.A.-J. designed research; G.C.S. performed research; G.C.S. analyzed data; G.C.S. wrote the paper.

This research was supported by National Institute on Drug Abuse Grants R01DA017289, R37DA06214, and T32 DA007288. We thank Michael Smith and Kimberely Fender for their excellent technical assistance.

Correspondence should be addressed to Dr. Gary S. Aston-Jones, Department of Neurosciences, Medical University of South Carolina, 171 Ashley Avenue, BSB 403, Charleston, SC 29425. E-mail: astong@musc.edu.

DOI:10.1523/JNEUROSCI.4561-11.2012

Copyright $\odot 2012$ the authors $\quad 0270-6474 / 12 / 324623-09 \$ 15.00 / 0$
Until recently, very little was known about input circuits that regulate orexin neurons. This issue was addressed by two studies in the last few years that mapped afferents to orexin neurons and the different orexin hypothalamic fields (Sakurai et al., 2005; Yoshida et al., 2006). Other studies showed that nucleus accumbens afferents to the LH orexin cell field are activated and involved in beer seeking (Marchant et al., 2009; Millan et al., 2010). However, it has not been determined whether other LH orexin afferents are involved in drug-related behaviors.

The objective of the current studies was to identify afferents to LH orexin neurons that are necessary for activating these cells and driving cocaine preference. Previous studies showed that LH and, specifically, LH orexin neurons receive inputs from lateral septum (LS) (Risold and Swanson, 1997b; Yoshida et al., 2006). Furthermore, LS and LH orexin neurons are responsive both to drugs of abuse (Shoji et al., 1997, 1998; Harris et al., 2007; Pasumarthi and Fadel, 2008) and to contextual information associated with reward (Harris et al., 2005; Takamura et al., 2006). Based on these previous findings, we sought to determine whether the LS to LH orexin circuit is important in cocaine conditioned place preference (CPP). Utilizing anatomical, pharmacological, antisense, and behavioral manipulations, we show that LS afferents to the LH orexin area are specifically activated during cocaine preference, and that LS influences on LH orexin neurons are necessary for this conditioned drug effect. These results provide a circuit for contextual information to modulate $\mathrm{LH}$ orexin neurons, and thereby regulate reward and drug abuse behaviors.

\section{Materials and Methods}

\section{Subjects}

Male Sprague Dawley rats (initial weight 300-325 g, Charles River) were pair-housed under a reversed $12 \mathrm{~h}$ light/dark cycle (lights off 6:00 A.M.) and had ad libitum access to food and water. Animals were housed in a temperature- and humidity-controlled animal facility at Medical University of South Carolina (MUSC) (Association for Assessment and Ac- 
creditation of Laboratory Animal Care-accredited). All experiments were approved by the Institutional Animal Care and Use Committee at MUSC and conducted according to specifications of the NIH as outlined in the Guide for the Care and Use of Laboratory Animals. A total of 141 rats were used in these experiments.

\section{Drug treatments}

Cocaine $\mathrm{HCl}$ (NIDA) was dissolved in $0.9 \%$ sterile saline. The OX1R antagonist SB-334867 (SB; 1-(2-methylbenzoxazol-6-yl)-3-[1,5]naphthyridin4 -yl urea hydrochloride, generously provided by NIDA) was suspended in $2 \%$ DMSO and $10 \%$ 2-hydroxypropyl- $\beta$-cyclodextrin (Sigma) in sterile water; 15 or $30 \mathrm{mg} / \mathrm{kg}$ was given in a volume of $4 \mathrm{ml} / \mathrm{kg}$ (intraperitoneally) 30 min before the preference test session. Vehicle was delivered at the same volume as the SB solution.

\section{Cannula surgeries and injections}

Retrograde tracing. Cholera toxin $\mathrm{b}$ subunit $(\mathrm{CTb})$ microinjections into LH were made using methods similar to those described in previous publications (Delfs et al., 1998; Chen et al., 1999). In brief, rats were anesthetized with ketamine/xylanine (56.5/8.7 mg/kg, i.p.) and placed in a stereotaxic apparatus. A midline scalp incision was made and a small hole was drilled through the skull above LH. With the dura removed, a glass pipette (10 $\mu \mathrm{m}$ tip diameter) was lowered into the LH orexin field [anteroposterior (AP) -2.8 , ML 1.7, DV -8.8 from skull surface), and $30 \mathrm{nl}$ of $\mathrm{CTb}$ ( $0.5 \%$ dissolved in $0.1 \mathrm{M}$ phosphate buffer, Sigma) was unilaterally delivered via pressure injection. The pipette was left in place for $15 \mathrm{~min}$ after the injection to allow for $\mathrm{CTb}$ diffusion and to minimize backflow up the pipette tract. CTb injections that diffused outside LH or PFA/DMH areas due to backflow up the pipette tract were not included in these studies. Animals were handled daily and allowed 1 week of recovery before behavioral testing.

Differences between rostral LS (LSr) and caudal LS (LSc) afferents to LH were noted in the tract-tracing studies. Based on these differences, we defined the rostral LS as (from bregma), AP 2.2-1.4, ML 0.8-0.3, DV - 4.85.6 from skull surface, and the caudal LS as (from bregma), AP 1.3-0.5, ML 0.9-0.3, DV $-4.8-5.7$ from skull surface (Paxinos and Watson, 1998).

LSr inactivation. Rats were deeply anesthetized and guide cannulae (22 gauge) were unilaterally or bilaterally placed $2 \mathrm{~mm}$ above LSr as described above. Guide cannulae were permanently fastened to the skull using acrylic cement and obturators were inserted to prevent blockage. Before the CPP test, injector cannulae (28 gauge) were lowered through and $2 \mathrm{~mm}$ below the guide cannulae to infuse artificial $\mathrm{CSF}(\mathrm{aCSF})(n=6)$ or the $\mathrm{GABA}_{\mathrm{A} / \mathrm{B}}$ receptor agonists baclofen plus muscimol (B-M, 0.3/ $0.03 \mathrm{nmol}$ in aCSF, $0.3 \mu \mathrm{l}, n=6$ and 7 for unilateral and bilateral studies, respectively). The injector cannulae were kept in place for 1 min to allow for diffusion of the drug. A counterbalanced within-subjects design was used in bilateral LS inactivation experiments. Missed B-M injections were used as anatomical controls in these bilateral inactivation studies $(n=8)$.

LS-LH orexin disconnection. Guide cannulae (22 gauge) were implanted with the tip of one $2 \mathrm{~mm}$ above one LS, and the other $2 \mathrm{~mm}$ above the ipsilateral or contralateral LH for unilateral control and bilateral disconnection studies, respectively. One day after the last conditioning session, an injector cannula (28 gauge) was inserted into LH to microinfuse orexin antisense (AS) (Vivo-Morpholino $0.15 \mathrm{nmol} / 0.3 \mu \mathrm{l}$ in $0.5 \mathrm{~mm}$
Table 1. Mean ( \pm SEM) number of crosses during CPP test

\begin{tabular}{ll}
\hline Group & Number of crosses \\
\hline Experiment 1 & \\
$\quad$ Vehicle & $42(4.7)$ \\
SB $(15 \mathrm{mg} / \mathrm{kg})$ & $52(5.3)$ \\
Vehicle & $46(3.0)$ \\
SB $(30 \mathrm{mg} / \mathrm{kg})$ & $40(3.1)$ \\
Experiment 3 & \\
aCSF & $39(5.3)$ \\
B-M & $44(6.4)$ \\
Missed B-M & $39(3.7)$ \\
Experiment 4 & \\
aCSF & $43(5.2)$ \\
B-M & $54(7.2)$ \\
Experiment 6 & \\
aCSF/AS & $40(4.0)$ \\
B-M miss/AS & $34(4.0)$ \\
aCSF/AS miss & $45(10.9)$ \\
B-M/Ctrl AS & $36(5.0)$ \\
B-M/AS & $38(8.5)$ \\
Unilateral B-M/AS & $45(7.6)$ \\
\hline
\end{tabular}
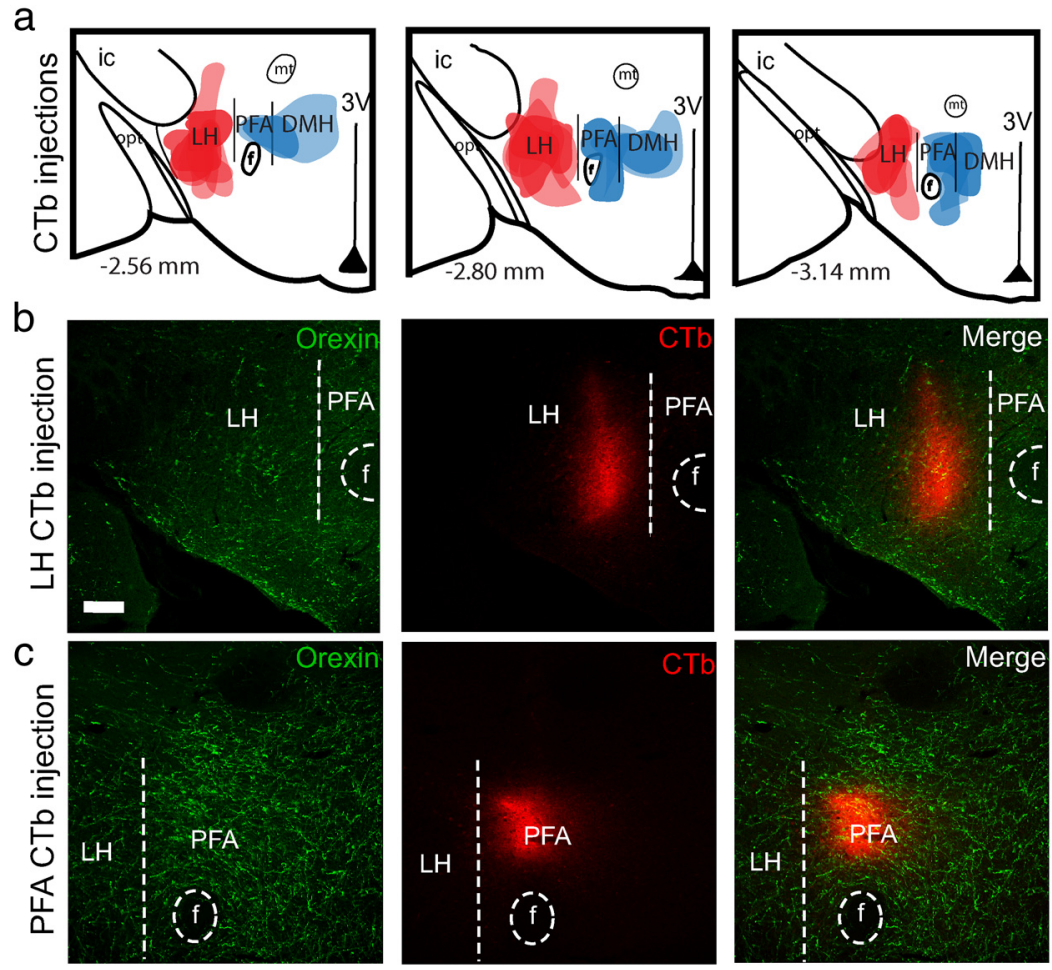

Figure 1. Injections of CTb in orexin cell fields. $\boldsymbol{a}$, Schematic representation depicting the extent of CTb diffusion at injection sites in LH (red) or PFA/DMH areas (blue). Each CTb injection was plotted at $50 \%$ opacity so that darker colors represent overlapping injection sites across animals. $\boldsymbol{b}, \boldsymbol{c}$, Representative immunofluorescence labeling for orexin (green) and (Tb (red) in LH (b) and PFA (c) orexin areas that received CTb injections. Scale bar, $200 \mu \mathrm{m}$.

phosphatebuffer, Gene Tools, 5' -GTATCTTCGGTGCAGTGGTCCAAA T-3') or control antisense (Ctrl AS) that targets a human $\beta$-globin intron mutation (Vivo-Morpholino standard control, $0.3 \mu \mathrm{l}$, Gene Tools, $5^{\prime}$ CCTCTTACCTCATTACAATTTATA-3'). Six days later (during peak orexin knockdown in LH; see below and Reissner et al., 2012), aCSF or $\mathrm{B}-\mathrm{M}(0.3 / 0.03 \mathrm{nmol}, 0.3 \mu \mathrm{l})$ was injected into LS $5 \mathrm{~min}$ before the CPP test session. Missed B-M or orexin antisense injections were used as anatomical controls in these bilateral disconnection studies. After behavioral testing, animals were killed, and orexin knockdown and cannulae placements were verified. These manipulations in $\mathrm{LSr} / \mathrm{LH}$ yielded the following groups with respective $n$-values: aCSF/AS $(n=6)$; missed B- 
a

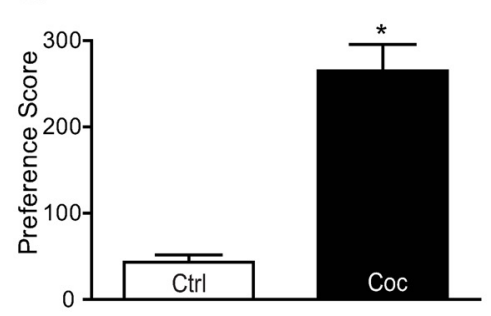

C

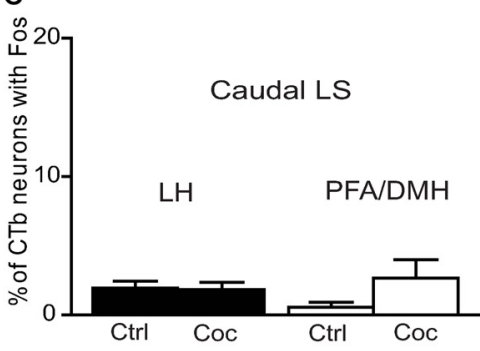

e

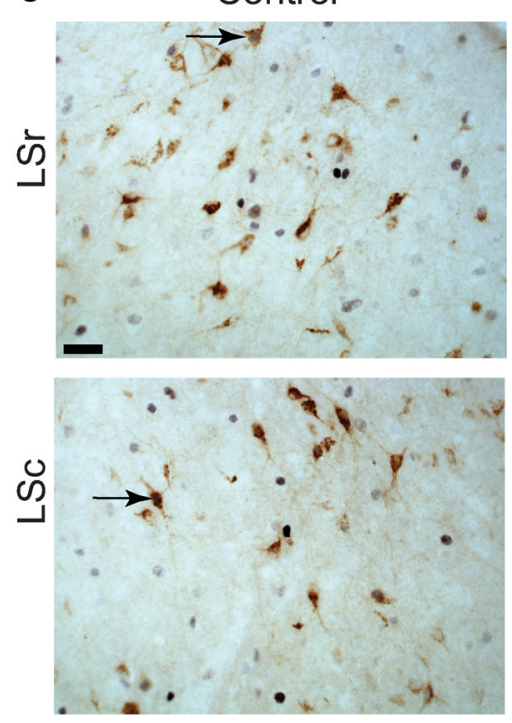

b

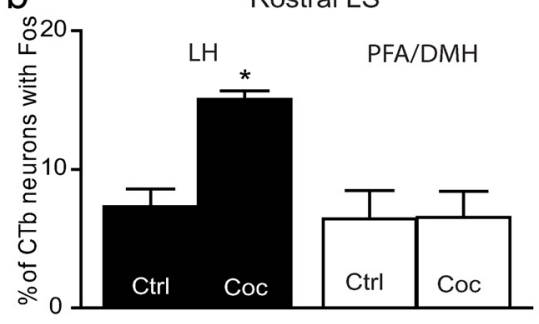

d

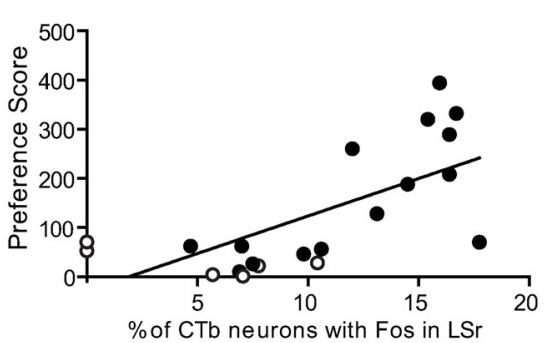

Cocaine

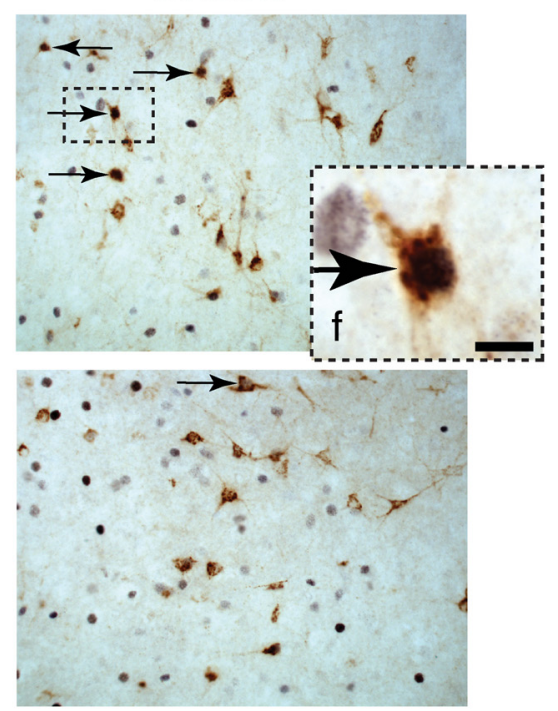

Figure 2. Rostral LS neurons that project to LH are activated during cocaine CPP. $\boldsymbol{a}-\boldsymbol{c}$, Conditioned place preference scores $(\boldsymbol{a})$ and activation of rostral $(\boldsymbol{b})$ and caudal $(\boldsymbol{c}) \mathrm{LS}$ afferents to $\mathrm{LH}$ and PFA/DMH orexin cell fields during cocaine (Coc) preference tests $\left({ }^{*} p=0.0002\right.$ indicates significant difference from LH Ctrl in LSr). Note significant preference and Fos induction in rostral, but not caudal, LS cells that project to LH but not those that project to PFA/DMH areas. $\boldsymbol{d}$, Significant positive correlation between preference scores and percentages of LH-projecting LSr neurons (CTb-labeled) that are double labeled with Fos (Pearson's correlation, $r=0.66,{ }^{*} p=0.001$ ). No correlation between preference scores and percentages of $\mathrm{LS}$ neurons that project to PFA/DMH areas was detected (data not shown). Open circles, saline conditioned; closed circles, cocaine conditioned. $\boldsymbol{e}$, Representative photomicrographs of $\mathrm{CTb}$ (brown neurons) and Fos labeling (black nuclei) following cocaine preference test show an increase in Fos expression in LSr, but not LSc, neurons that project to the LH orexin area. Double-labeled CTb/Fos neurons are indicated with black arrows. Scale bar, $100 \mu \mathrm{m}$. $\boldsymbol{f}$, High-magnification inset of the field depicted in $\boldsymbol{e}$, upper right, showing a Fos-positive CTb neuron in LSr. Scale bar, $20 \mu \mathrm{m}$. LH Ctrl $n=13, \mathrm{LH}$ Coc $n=8, \operatorname{PFA} /$ DMH Ctrl $n=7, \operatorname{PFADMHCOC} n=6$.

M/AS $(n=7) ; \mathrm{aCSF} /$ missed AS $(n=8) ; \mathrm{B}-\mathrm{M} / \mathrm{C} t r l$ AS $(n=6) ; \mathrm{B}-\mathrm{M} / \mathrm{AS}$ $(n=6)$, and unilateral B-M/AS $(n=8)$.

\section{Orexin antisense}

To confirm the effectiveness of orexin knockdown, a separate group of animals received unilateral LH injections of orexin antisense or control antisense, as described above. Animals were killed and perfused 6 or $14 \mathrm{~d}$ after injection ( $6 \mathrm{~d}$ postinjection: $n=7$ for orexin AS and control AS, $14 \mathrm{~d}$ postinjection: $n=8$ for orexin AS) and LH sections were stained for orexin or melanin concentrating hormone $(\mathrm{MCH})$, a neuropeptide that is localized in $\mathrm{LH}$ but not in orexin neurons.

\section{Conditioned place preference}

$\mathrm{CPP}$ experiments followed procedures previously used by our laboratory (Harris and AstonJones, 2003; Harris et al., 2005, 2007). The CPP apparatus consisted of two distinct compartments that were separated by a removable partition. One compartment had a grid floor with solid black walls, and the second compartment consisted of a mesh floor with black and white striped walls. The compartments were equipped with 8 photocell beams that automatically measured activity and time on each side. The CPP chambers were located in environmental isolation boxes to reduce outside distraction. On the first day (pretest), the partition had a doorway that allowed the animal to have free access to both sides of the chamber for $15 \mathrm{~min}$, and the time spent on each side was recorded automatically. None of the animals displayed an initial bias in this pretest session $(<100 \mathrm{~s}$ time difference between sides). Two days later, animals were conditioned for 3 consecutive days. During conditioning the animals were injected with cocaine $(10 \mathrm{mg} / \mathrm{kg}$ ) or saline and confined to one side of the chamber by a solid partition for $30 \mathrm{~min}$. As in previous studies in our laboratory, conditioning occurred in morning and afternoon sessions (at least $4 \mathrm{~h}$ apart) (Harris and Aston-Jones, 2003; Harris et al., 2005, 2007). Control animals received an injection of saline on each side of the chamber on conditioning days $(n=6)$. Additionally, cocaine-conditioned rats that did not show a preference $(<75 \mathrm{~s}$ more time on the cocaine side) were included in the control group in the tract-tracing experiments $(n=7)$. Two to $6 \mathrm{~d}$ after the last conditioning session, animals were tested for cocaine preference in a 15 min session with free access to both sides of the chamber. The preference score was calculated as the time spent on the cocaine side minus the time spent on the saline side. Animals that were saline conditioned or cocaine conditioned and did not show preference were combined because there was no difference in preference scores $\left(t_{(11)}=0.45, p=0.7\right)$ or percentage of $\mathrm{CTb}$ neurons that were Fospositive in LS $\left(t_{(11)}=1.5, p=0.2\right)$ between these groups. Where mentioned, a counterbalanced within-subject design was used to test for cocaine preference in some groups.

\section{Immunohistochemistry}

Procedures to stain for Fos, orexin, $\mathrm{CTb}$, and $\mathrm{MCH}$ were similar to those published previously by our laboratory (Delfs et al., 1998; Harris et al., 2005, 2007). For Fos staining in CTb- or orexinpositive neurons, rats were deeply anesthetized with ketamine/xylanine $(100 / 20 \mathrm{mg} / \mathrm{kg}$, i.p.) 90 min after the conditioned place preference test and were then perfused transcardially with cold $0.9 \%$ saline followed by $4 \%$ paraformaldehyde. Brains were cut into $40-\mu \mathrm{m}$ thick tissue sections and processed to visualize Fos or orexin. Fos was visualized by incubating the sections in rabbit anti-Fos (1:5000, Santa Cruz Biotechnology) overnight, incubation in biotinylated donkey anti-rabbit secondary antibody (1:500, Jackson ImmunoResearch Laboratories) for $2 \mathrm{~h}$, and incubation in avidin-biotin complex (ABC, 1:500) for $1.5 \mathrm{~h}$. Finally, sections were incubated in 3,3'-diaminobenzidine (DAB, Sigma) and nickel ammonium sulfate, producing a purple-black reaction product in the nucleus. Subsequently, CTb was visualized by incubating the same tissue sections in goat anti-CTb (1:20,000, List Biological Laboratories) overnight, and 
then biotinylated donkey anti-goat secondary (1: 500, Jackson ImmunoResearch Laboratories), followed by ABC (1:500). Finally, sections were incubated in $\mathrm{DAB}$ to yield a brown reaction product in the cytoplasm. For visualization of Fos in orexin neurons, Fos was stained as described above followed by incubation in goat anti-orexin (1:1000, Santa Cruz Biotechnology), biotinylated donkey anti-goat (1:500), and avidin-biotin complex (1:500). Finally, sections were incubated in $\mathrm{DAB}$ to produce a brown reaction produce in the cytoplasm.

To confirm LH orexin antisense-mediated knockdown, tissue was processed for the visualization of orexin and $\mathrm{MCH}$. MCH was visualized by incubating sections in rabbit anti-MCH (1: 2500 Phoenix Pharmaceuticals), biotinylated goat anti-rabbit antibody (1:500, Jackson ImmunoResearch Laboratories) for $2 \mathrm{~h}$, and avidinbiotin complex (1:500) for $1.5 \mathrm{~h}$. Detection of $\mathrm{MCH}$ was performed with DAB-nickel, as described above for Fos. Subsequently, orexin was visualized as described above. Tissue sections were mounted on glass slides, dehydrated in alcohols, and coverslipped.

To confirm that $\mathrm{CTb}$ injections were localized in an orexin cell field, tissue sections were reacted with rabbit anti-orexin and goat anti-CTb antibodies as described above and then incubated for $2 \mathrm{~h}$ in Alexa Fluor 488 anti-rabbit and Alexa Fluor 594 anti-goat secondary antibodies (1: 500, Invitrogen). Tissue sections were mounted on glass slides with Fluoromount (Electron Microscopy Sciences) and coverslipped.

\section{Histological verification of cannula sites}

For brain regions that were not immunohistochemically stained, pontamine sky blue ( $2 \%$ in $0.5 \mathrm{M} \mathrm{Na}$ acetate, $300 \mathrm{nl}$ ) was injected through the cannulae before perfusion and sections were mounted directly on slides and counterstained with neutral red to confirm cannulae placements.

\section{Data analysis}

GraphPad Prism v5 was used for statistical analysis. Data are expressed as means $( \pm$ SEM). Preference scores were analyzed by calculating the time spent in the cocaine-paired side minus the time spent in the saline-paired side during the CPP test. The resulting preference scores were compared within or between groups using Student's $t$ test or ANOVA.

The percentages of CTb neurons with Fos, or orexin neurons with Fos, were averaged across two sections per animal and compared between control and cocaine groups, or vehicle and B-M groups, using Student's $t$ tests. The cell counts for all experiments were manually counted by a blind observer with a point-counter using Openlab image processing software (Improvision, Ltd.) on a Macintosh computer that was linked to a microscope and digital camera. CTb-positive neurons were counted in the LS, ipsilateral and contralateral to the injection site. However, because the number of CTb-positive neurons in the contralateral LS was negligible ( $\leq 3 \mathrm{CTb}$-positive neurons per section), only counts in the ipsilateral hemisphere are reported. Correlations between percentages of $\mathrm{CTb}$ neurons that were Fos + and preference scores were obtained using Pearson's correlation coefficient test.

In the orexin antisense studies, counts of orexin and $\mathrm{MCH}$ neurons in $\mathrm{LH}$ and PFA/DMH areas were compared in injected (orexin antisense, control antisense, and $14 \mathrm{~d}$ recovery from orexin antisense) or noninjected sides across 4 sections per animal. Counts of remaining orexin neurons were compared between groups using a one-way ANOVA. When a significant $F$-value was obtained, pairwise comparisons were performed using a NewmanKeuls test.

\section{Results}

\section{Experiment 1: OX1R antagonist attenuates expression of} cocaine place preference

Rats were given cocaine CPP conditioning as described in Materials and Methods. To examine the role of OX1Rs in the expression of
Table 2. Mean ( \pm SEM) number of CTb-, Fos-, and CTb/Fos-labeled neurons after CTb injections in LH or PFA/DMH in cocaine and control animals

\begin{tabular}{|c|c|c|c|c|c|c|}
\hline & \multicolumn{3}{|l|}{$\mathrm{LSr}$} & \multicolumn{3}{|l|}{ LSC } \\
\hline & $\begin{array}{l}\text { Number of } \\
\text { CTb only }\end{array}$ & $\begin{array}{l}\text { Number of Fos } \\
\text { only }\end{array}$ & $\begin{array}{l}\text { Number of } \\
\text { CTb/Fos }\end{array}$ & $\begin{array}{l}\text { Number of } \\
\text { CTb only }\end{array}$ & $\begin{array}{l}\text { Number of } \\
\text { Fos only }\end{array}$ & $\begin{array}{l}\text { Number of } \\
\mathrm{CTb} / \text { Fos }\end{array}$ \\
\hline $\mathrm{ctrl}$ & $34.4(3.3)$ & $63.8(5.3)$ & $2.6(1.2)$ & $37.1(6.8)$ & $43(7.0)$ & $1.1(0.2)$ \\
\hline LS COC & $44.0(6.2)$ & $60.1(6.7)$ & $6.7(1.0)^{*}$ & $49.0(8.8)$ & $35.1(5.7)$ & $1.4(0.4)$ \\
\hline PFA/DMH ctrl & $27.1(6.1)$ & $59.4(16.4)$ & $2.2(0.9)$ & $16.6(7.3)$ & $57.2(13.8)$ & $0.2(0.2)$ \\
\hline PFA/DMH coc & $32.5(4.2)$ & $61.3(4.6)$ & $2.3(0.8)$ & $12.1(3.0)$ & $37.7(6.3)$ & $0.4(0.2)$ \\
\hline
\end{tabular}

coc, Cocaine.

${ }^{*} \mathrm{LH} \operatorname{coc}>\mathrm{LH}$ ctrl in number of $\mathrm{CTb} / \mathrm{Fos}, p<0.01$.

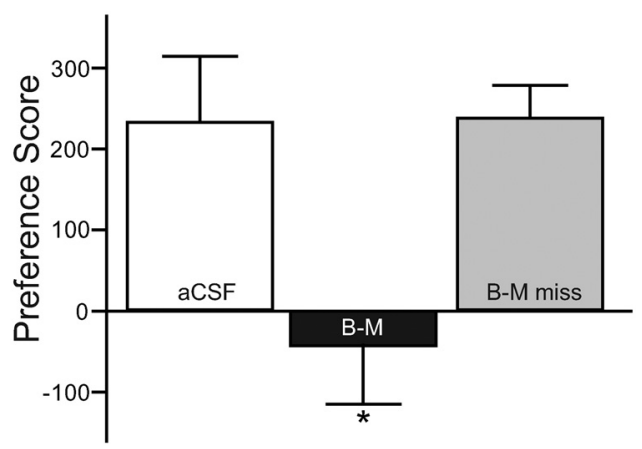

Figure 4. The $L S$ is necessary for cocaine preference. Cocaine-conditioned animals received bilateral injections of B-M or aCSF into LSr before a CPP preference test $(n=7)$. Injections of $B-M$ outside of $L S$ were used as an anatomical control (B-M miss, $n=8$ ). Bilateral microinjections of B-M into $\mathrm{LSr}$ significantly attenuated cocaine preference. *Significantly different from aCSF and B-M misses, ${ }^{*} p<0.05$, using one-way ANOVA followed by Newman-Keuls post hoc tests.

cocaine preference, conditioned rats received an injection of the OX1R antagonist SB-334867 (15 or $30 \mathrm{mg} / \mathrm{kg}$, i.p.) or vehicle $30 \mathrm{~min}$ before the preference tests in a within-subjects design. We found that SB-334867 at $30 \mathrm{mg} / \mathrm{kg}$ blocked expression of cocaine preference compared with vehicle (Veh $248 \pm 43$; SB $26 \pm 57, t_{(6)}=3.1, p=$ 0.02; paired $t$ test, $n=7$ ) whereas $15 \mathrm{mg} / \mathrm{kg} \mathrm{SB}-334867$ did not significantly attenuate preference for the cocaine-paired side (Veh $318 \pm 51$; SB $207 \pm 34, t_{(7)}=2.1, p=0.07$; paired $t$ test, $\left.n=8\right)$. This treatment had no significant effect on general motor activity ( $t$ values $<1.6, p>0.05$ ), as measured by the number of crosses between the two chambers (Table 1). 
a
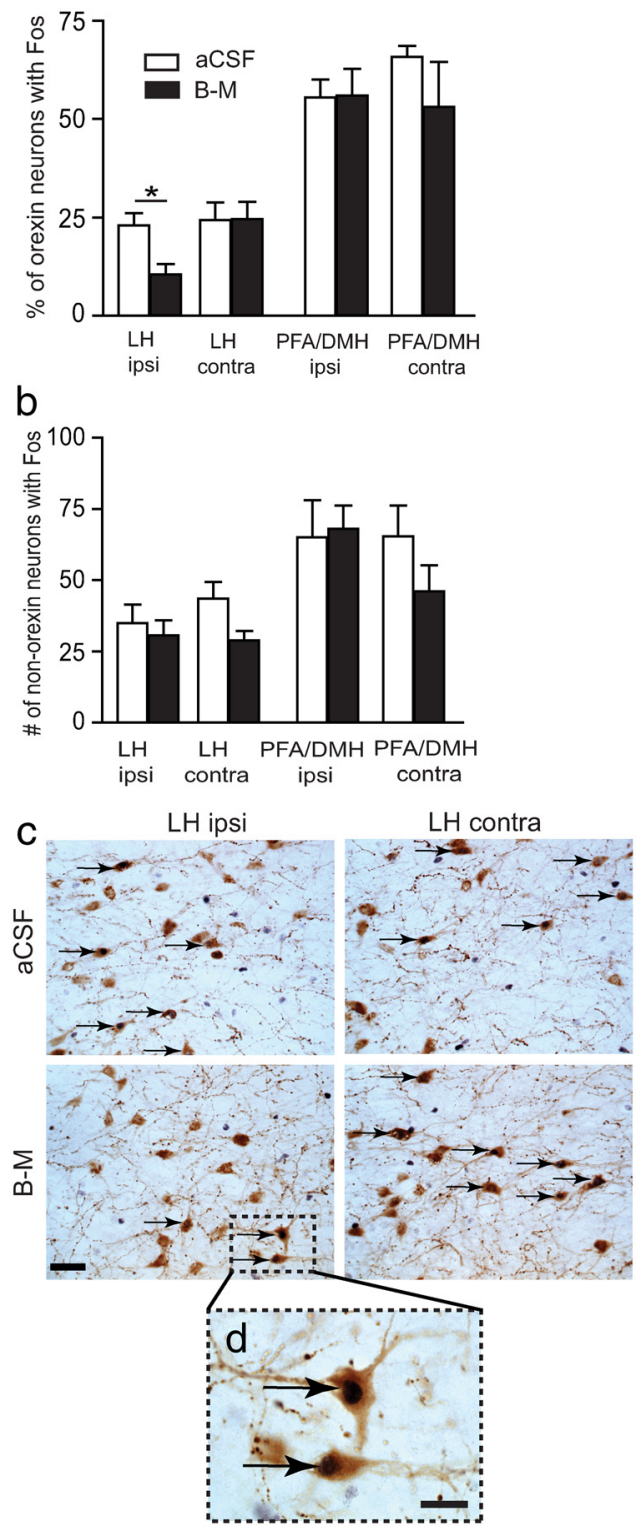

Figure 5. Effects of $L S$ inhibition on Fos in orexin neurons during cocaine CPP. $\boldsymbol{a}, \boldsymbol{b}$, Unilateral inhibition of $L S$ with B-M selectively attenuated Fos induction in ipsilateral $L H$ orexin neurons, but not in PFA/DMH orexin neurons or non-orexin neurons, during cocaine CPP test $\left({ }^{*} p=0.01\right.$ indicates a significant difference when comparing B-M to aCSF in ipsilateral $L H, n=6 ; t$ test). , Representative photomicrographs of orexin (brown cytoplasm) and Fos labeling (black nuclei) in LH following unilateral injections of aCSF or B-M in to LSr. Note a substantial reduction in the number of $L H$ orexin neurons with Fos ipsilateral to B-M injection in $L S$ (double-labeled neurons indicated with black arrows). Scale bar, $100 \mu \mathrm{m}$. $\boldsymbol{d}$, High-magnification inset of the field depicted in c, lower left, showing orexin/Fos-positive cells in LH. Scale bar, $30 \mu \mathrm{m}$.

\section{Experiment 2: Afferents to the LH orexin field from LSr are activated during cocaine preference}

Rats were injected with a unilateral microinjection of the retrograde tracer CTb in an orexin cell field (LH, PFA, or DMH), as described in Materials and Methods (Fig. 1). Two weeks later animals were subjected to cocaine CPP and perfused 90 min after the corresponding preference test, and tissue through LS was stained for Fos and CTb. In this way, we sought to determine whether LS afferents to orexin cell fields were activated (as seen by Fos induction) during expression of cocaine preference. In animals expressing a cocaine preference $(n=8), 16 \%$ of LSr and 3\%

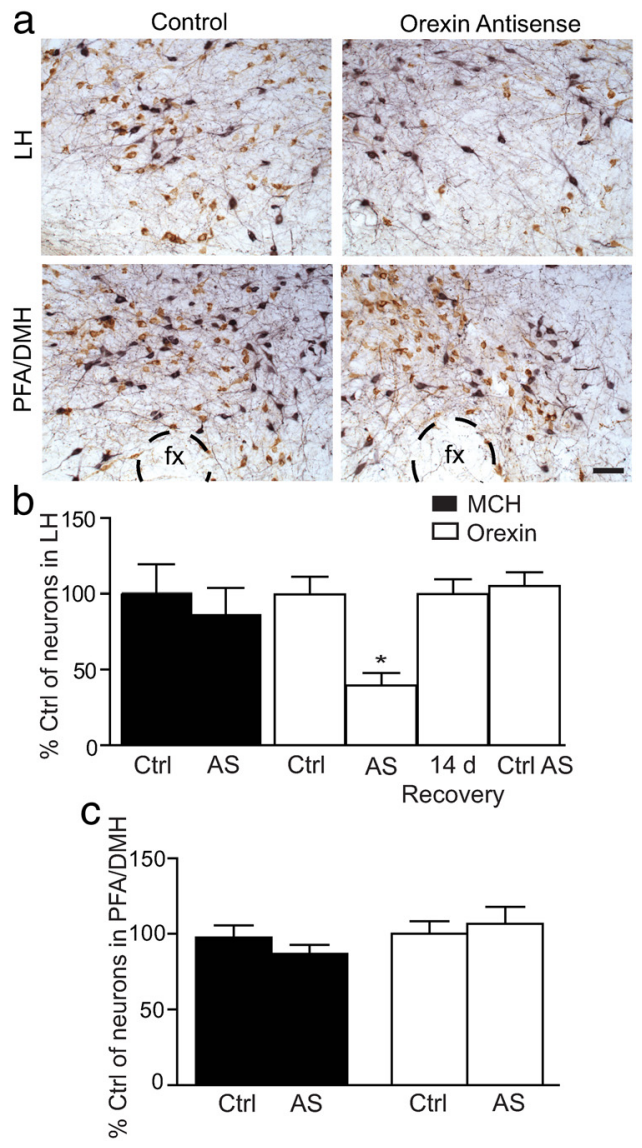

Figure 6. Orexin A antisense selectively decreases orexin expression. $\boldsymbol{a}$, Representative photomicrographs of orexin (brown) and MCH (black) labeling in LH and PFA/DMH areas following unilateral orexin AS injection in LH. Noninjected hemispheres of the same sections were used for control measurements ( $(\mathrm{trl} n=7)$. Note the substantial reduction in the number of $\mathrm{LH}$ orexinstained but not MCH-stained neurons following antisense injection in $\mathrm{LH}$ (LH antisense side, $n=7) \cdot \boldsymbol{b}$, A significant reduction in the number of orexin neurons, but not MCH neurons, was detected following orexin antisense injections in $\mathrm{LH}\left({ }^{*} p<0.001\right.$ indicates significant difference from orexin (trl, $14 \mathrm{~d}$ recovery, and Ctrl AS using one-way ANOVA followed by Newman-Keuls post hoc tests). Injections of (trl AS (antisense for human $\beta$-globin intron mutation, $n=7$ ) in LH did not attenuate orexin expression compared with (trl. Orexin expression returned to control levels $14 \mathrm{~d}$ after orexin antisense injection in LH ( $14 \mathrm{~d}$ Recovery, $n=8)$. c, Orexin and MCH staining in PFA/DMH areas were unaffected by orexin antisense injections in $\mathrm{LH}$ Scale bar, $100 \mu \mathrm{m}$.

of LSc afferents to the LH orexin area were activated during cocaine preference, compared with $8 \%$ and $3 \%$ in LSr and LSc of control animals $(n=13)$, respectively (Fig. $2 b, c)$. A significant Fos activation of LH-projecting neurons was specifically found in rostral $\left(t_{(19)}=4.6, p=0.0002\right)$, but not caudal, LS $\left(t_{(11)}=0.09\right.$, $p=0.9$; Student's $t$ tests) (Fig. 3b,c,e; Table 2). Correlation analysis revealed that the percentages of LH-projecting $(\mathrm{CTb}+)$ neurons that were Fos-activated in LSr were positively correlated with the preferences that corresponding animals exhibited on the CPP test day (Pearson's correlation: $r=0.66 p=0.001)($ Fig. $2 d)$. Additionally, when saline-conditioned animals were removed from this analysis, a significant positive correlation was also found between preference scores and percentages of LHprojecting neurons with Fos in LSr in cocaine-conditioned animals (Pearson's correlation: $r=0.51, p=0.003)$. $\operatorname{LSr}(n=6)$ or LSc $(n=7)$ neurons that project to the PFA/DMH orexin area did not show an increase in Fos activation during the cocaine CPP test, indicating that these results were specific for afferents to $\mathrm{LH}$ ( $t$ values $<1.3, p>0.05$ ) (Fig. $2 c$; Table 2). No difference in the 
number of CTb-positive neurons or non$\mathrm{CTb}$ neurons with Fos was found between groups using a one-way ANOVA ( $F$ values $<1.7, p>0.05$, Table 2).

\section{Experiment 3: Inhibition of LSr} attenuates cocaine preference

Next we sought to examine whether LSr bilaterally is necessary for cocaine preference. Bilateral cannulae were directed at $\mathrm{LSr}$ and animals were conditioned in Cocaine CPP (Fig. 3). We found that inactivation of LSr by local microinjections of B-M before the CPP test significantly attenuated cocaine preference compared with aCSF $(n=7)$ or injections of B-M outside of LS $(n=8)$ (one-way ANOVA: $F_{(2,19)}=5.9, p=0.01$ ) (Fig. 4). No significant effect on general motor activity was observed between groups by one-way $\operatorname{ANOVA}\left(F_{(2,19)}=0.3, p>0.05\right)$ as measured by the number of crosses between the two chambers (Table 1).

Experiment 4: Inhibition of LSr reduces orexin neuronal activity specifically in $\mathrm{LH}$

To determine whether LSr projections activate LH orexin neurons (as indexed by Fos induction) during the expression of $\mathrm{CPP}$, animals received a unilateral cannula directed at LSr and were then conditioned in cocaine CPP. Before the CPP test, conditioned animals received a unilateral infusion of the $\mathrm{GABA}_{\mathrm{A} / \mathrm{B}}$ receptor agonist cocktail B-M (to inhibit neuronal activity) or aCSF through this cannula (Fig. 3; $n=6$ ). Ninety minutes following the preference test, animals were perfused and hypothalamic sections were immunohistochemically stained for orexin and Fos. Compared with vehicle injections, we found that unilateral infusion of B-M into LSr before the CPP test significantly reduced Fos expression selectively in LH orexin neurons ipsilateral (Student's $t$ test: $\left.t_{(10)}=3.1 p=0.01\right)$, but not contralateral $\left(t_{(10)}=0.02, p=0.9\right)$, to the injected side (Fig. 5). No significant changes in Fos expression in PFA/DMH orexin, or in non-orexin neurons in any orexin cell field, were detected ( $t$ values $<1.6, p>0.05$ ). No differences in preference scores were observed between unilateral $\mathrm{B}-\mathrm{M}$ or aCSF injections in LSr (average preference scores for aCSF $222 \pm 84$ vs B-M $\left.194 \pm 28 ; t_{(10)}=0.6, p=0.5\right)$, indicating that the decrease in Fos was not due simply to decreased preference behavior, and that intact LS to LH projections in one hemisphere is sufficient for preference expression.

\section{Experiment 5: Selective knockdown of orexin in LH using orexin $A$ antisense}

Orexin A antisense was used to selectively knockdown orexin in LH neurons. Animals received a unilateral injection of orexin
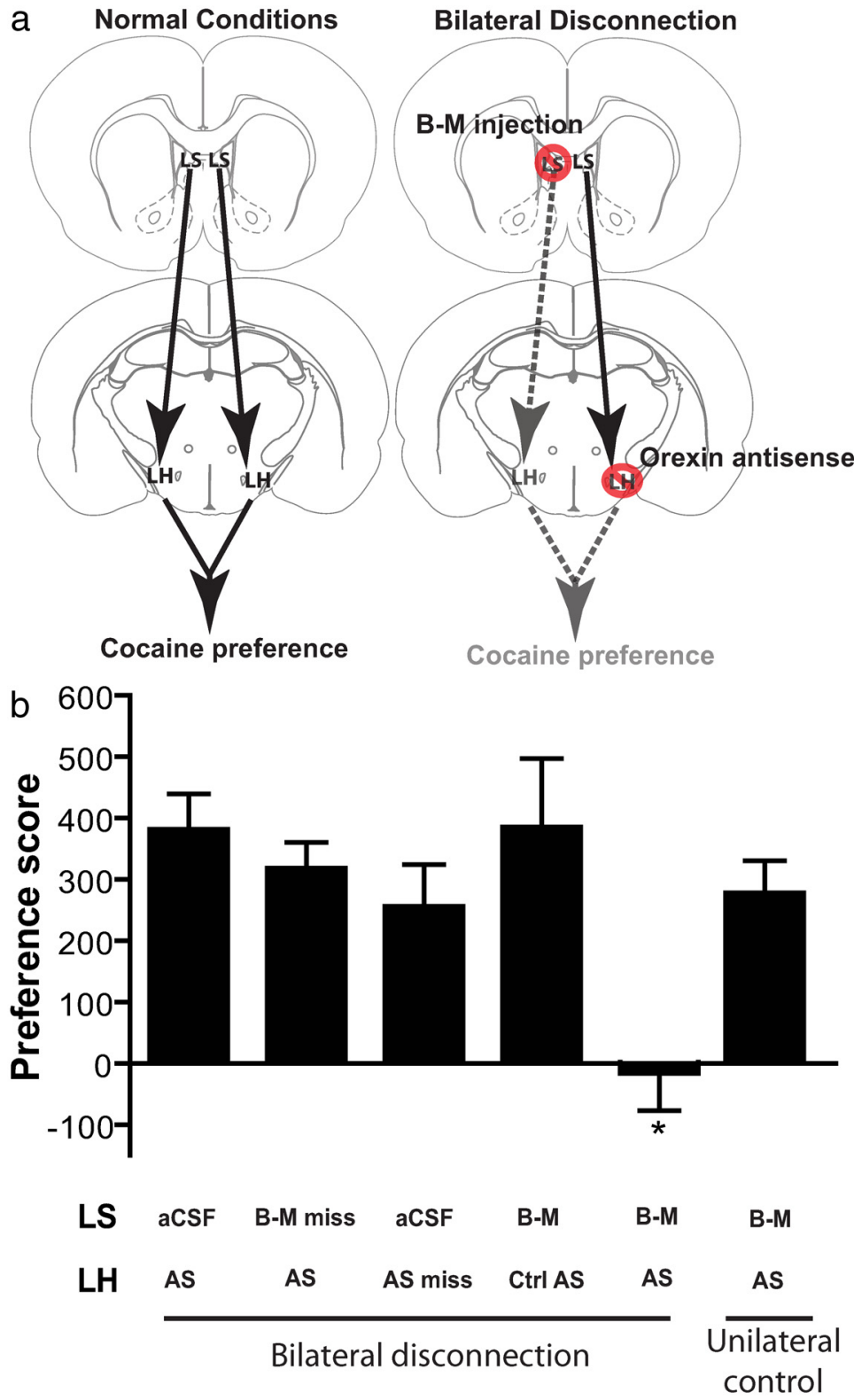

Figure 7. Bilateral disconnection of $L S$ and $L H$ orexin neurons blocks expression of cocaine preference. $\boldsymbol{a}$, Schematic of bilateral disconnection showing unilateral inhibition of orexin expression in $\mathrm{LH}$ orexin neurons with orexin antisense and contralateral inhibition of $L S$ with B-M before the preference test. $\boldsymbol{b}$, Cocaine preference was significantly attenuated following knockdown of orexin in LH with orexin AS and inhibition of contralateral LS with B-M ${ }^{*} p<0.01$ indicates significant difference from all other groups using one-way ANOVA followed by Newman-Keuls post hoc tests). Control injections of aCSF, missed B-M injections nearby in LSr and orexin AS in ipsilateral LH did not reduce cocaine preference. $n$-values for each group: aCSF/AS $(n=6)$; missed B-M/AS $(n=7) ; \mathrm{aCSF} /$ missed AS $(n=8) ; \mathrm{B}-\mathrm{M} / \mathrm{Ctrl} \mathrm{AS}(n=6)$; bilateral B-M/AS $(n=6)$, and unilateral B-M/AS $(n=8)$.

antisense $(n=7)$ or control antisense $(n=7)$ and were killed $6 \mathrm{~d}$ postinjection. Additional animals that received orexin antisense injections were killed $14 \mathrm{~d}$ postinjection to examine recovery of orexin expression $(n=8)$. Immunohistochemical staining for orexin A and MCH (localized in LH but not colocalized in orexin neurons) (Elias et al., 1998) was performed to verify the specificity of orexin knockdown. We found that injection of orexin A antisense into $\mathrm{LH}$ selectively reduced the number of neurons expressing orexin $6 \mathrm{~d}$ postinjection compared with the noninjected control hemisphere, control antisense, or $14 \mathrm{~d}$ postantisense injections (14 d recovery) in LH (one-way ANOVA: $F_{(3,25)}=10.1, p=0.0002$ ) (Figs. $\left.6 a, b\right)$. No change in the number 

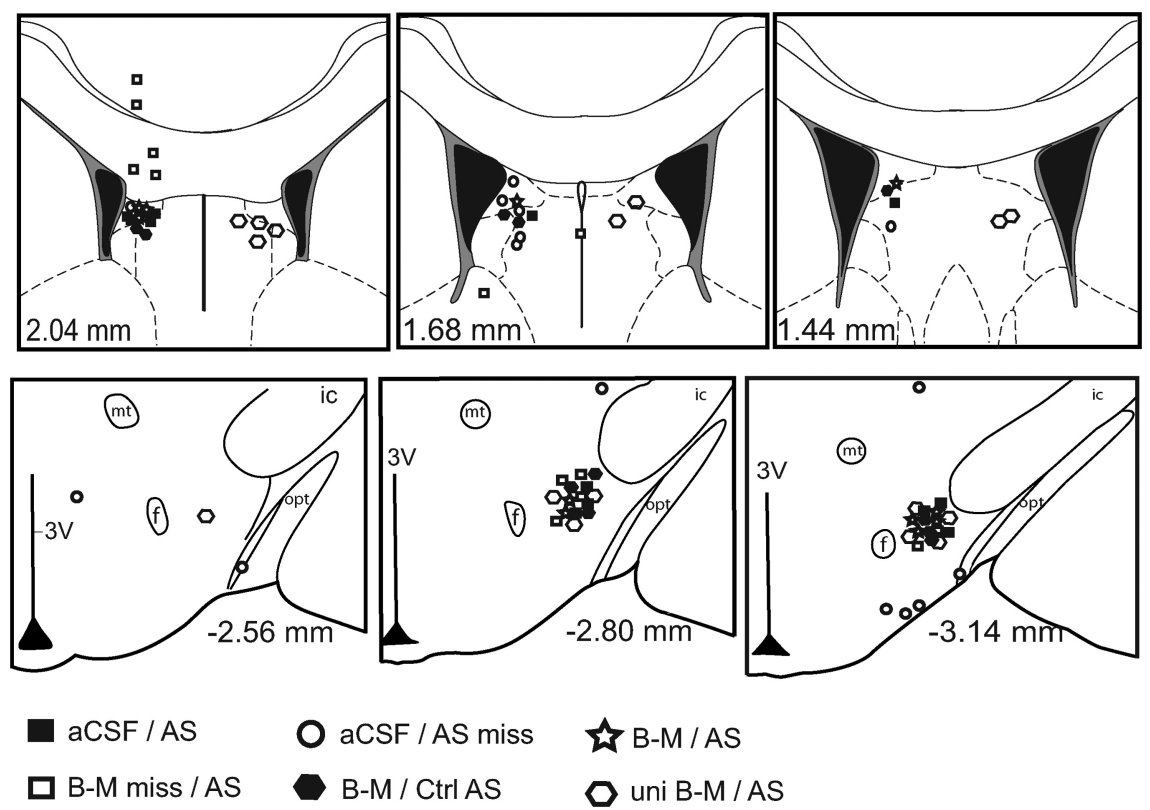

Figure 8. Cannulae placements in $L S$ and $L H$ in bilateral disconnection experiments. aCSF or B-M was injected unilaterally into LS and orexin AS or negative Ctrl AS was injected into the ipsilateral LH (unilateral control) or contralateral LH. Injections of B-M outside of LS (B-M miss) and antisense injections outside of LH (AS miss) were used as anatomical controls. Each shape in the legend indicates a group of animals. For example, injections of aCSF in $\mathrm{LS}$ and orexin antisense in contralateral $\mathrm{LH}$ are indicated by black squares, whereas injections of B-M in $L S$ and orexin antisense in ipsilateral $L H$ are represented with open hexagons.

of orexin neurons in PFA/DMH areas or number of MCH neurons in LH was observed (one-way ANOVA $F$ values $<1, p>$ 0.05 ) (Fig. 6c). A recovery of orexin expression in LH to control levels was observed $14 \mathrm{~d}$ after orexin antisense injection (Ctrl vs 14 d recovery: Student's $t$ test: $\left.t_{(13)}=0.01, p=0.9\right)($ Fig. $6 b)$.

\section{Experiment 6: LS regulation of LH orexin neurons is necessary for cocaine preference}

We used a bilateral disconnection technique to determine whether LS regulation of LH orexin neurons specifically is necessary for cocaine CPP expression ( $n=6-8$ per group) (Fig. $7 a$ ). Using orexin A antisense, conditioned animals received a unilateral knockdown of orexin in LH. Control antisense injections in $\mathrm{LH}$ and orexin antisense injections outside of $\mathrm{LH}$ were used as controls (Fig. 8). Six days after the antisense injection (during peak orexin knockdown) (Reissner et al., 2012), animals received a unilateral injection of B-M or aCSF in contralateral LS, and then were tested for cocaine preference. B-M injections outside of LS were also used as an anatomical control for bilateral disconnection studies (Fig. 8). Unilateral injections of orexin antisense in LH and B-M in ipsilateral LS were used as an additional control group. Bilateral disconnection of LSr-LH had a significant effect on preference scores (one-way ANOVA: $F_{(5,36)}=4.3, p=0.004$ ). Post hoc tests of significance demonstrated a significant difference in preference scores between the bilateral disconnection group (B-M/AS) compared with all other groups (Newman-Keuls test, $p<0.01$ ), but preference scores in the control experiments (aCSF/AS, missed B-M/AS, aCSF/missed AS, B-M/Ctrl AS, and unilateral B-M/AS) did not differ from each other (NewmanKeuls test, $p>0.05$ ) (Fig. $7 b$ ). No significant effect on general motor activity was observed between groups (one-way ANOVA: $\left.F_{(5,36)}=0.5, p>0.05\right)$, as measured by the number of crosses between the two chambers (Table 1).

\section{Discussion}

In the current studies we provide evidence that orexin, the LSr, and LSr-LH orexin circuits are importantly involved in cocaine CPP. First, we demonstrated that blockade of OX1R attenuates cocaine preference. Second, we revealed that $\mathrm{LSr}$ afferents to the LH orexin area were Fosactivated during the expression of cocaine preference, and that this Fos activation was correlated with preference scores. Third, we showed that inactivation of LSr with B-M blocked cocaine preference and selectively reduced Fos expression in LH orexin neurons during CPP test. Finally, we showed that inactivation of LSr, combined with decreased expression of orexin in contralateral LH, blocked cocaine preference. Together, these results indicate that LSr and LSr-LH orexin circuits are necessary for cocaine CPP.

\section{OX1R transmission is necessary for cocaine preference}

Previous studies found that LH orexin Fos activity is elevated with cocaine preference (Harris et al., 2005), but it was unclear whether orexin is necessary for cocaine preference. Using the OX1R antagonist SB-334867, we showed that activation of OX1R is necessary for cocaine preference. The effective dose of SB $(30 \mathrm{mg} / \mathrm{kg})$ did not affect the animal's ability to perform the task, as there were no differences in the number of crosses between chambers during the test. Recently, Sharf and colleagues reported that SB-334867 $(20 \mathrm{mg} / \mathrm{kg})$ did not attenuate cocaine preference in mice (Sharf et al., 2010); this may be due to the lower dose used in that study, or indicate possible species differences in orexin's involvement in cocaine CPP. In any case, our results are consistent with previous data showing that OX1R is important in several drug-seeking behaviors in rats (Boutrel et al., 2005; Lawrence et al., 2006; Smith et al., 2009, 2010).

\section{LS afferents to LH orexin field are involved in cocaine preference}

We found that LSr afferents to the LH orexin area, but not inputs to the adjacent PFA/DMH areas, were activated during cocaine preference. In addition, activity in these LH afferents was positively correlated with cocaine preference, indicating that LS projections to $\mathrm{LH}$ are involved in cocaine preference. Furthermore, we demonstrated that the Fos response in LSr neurons projecting to LH was dependent on a preference for the cocaine-paired side, as cocaine-conditioned animals without a preference did not show increased Fos induction. In addition, we showed that unilateral inactivation of LS during the CPP test reduced Fos activity selectively in LH orexin neurons ipsilateral to the injection, providing further evidence that LS activates LH orexin neurons during cocaine preference. These findings are consistent with previous studies showing that Fos activity in LH orexin neurons was increased with cocaine preference (Harris et al., 2005). In our results, LSc afferents to LH, however, were not Fosactivated during CPP test, indicating that these projections may not be important in regulating $\mathrm{LH}$ orexin neurons during cocaine CPP.

Additional studies here revealed that bilateral inactivation of LS blocked expression of cocaine preference. These results were 
consistent with previous findings that showed LS neurons are involved in both context and reward associations (Shoji et al., 1997; Takamura et al., 2006; Luo et al., 2011). Finally, we used a bilateral disconnection method with orexin antisense unilaterally in LH and inactivation of contralateral LS with B-M to confirm that an influence of LS afferents on LH orexin neurons is necessary for cocaine preference.

To our knowledge, this is first paper that specifically targets orexin neurons to determine which circuits regulate $\mathrm{LH}$ orexin neurons during cocaine-seeking behaviors. However, other tracttracing studies have found that afferents to the LH orexin area are activated during context-induced reinstatement of cocaine- or beer-seeking in instrumental drug-seeking paradigms (Hamlin et al., 2008; Marchant et al., 2009). Specifically, the nucleus accumbens shell (NAcS) and its interactions with LH orexin neurons were found to be involved in the reinstatement of beer-seeking (Marchant et al., 2009; Millan et al., 2010). Although several differences between these studies and our current paradigm exist (beer vs cocaine, instrumental vs Pavlovian tasks, extinction vs no extinction), it would be interesting to determine whether NAcS projections to $\mathrm{LH}$ orexin neurons are important in cocaine CPP.

The bilateral disconnection technique is a useful method to reveal neural connections involved in specific behaviors (Harris et al., 2007). One caveat of this technique is that it does not differentiate between afferents and efferents. In other words, one might argue that our results were due to interruption of projections from LH orexin neurons to LS. However, this alternative explanation is not likely due to the fact that there are virtually no orexin receptors in LS (Marcus et al., 2001). Another possible caveat in the bilateral disconnection technique is that intermediary synaptic connections may be involved between the areas manipulated. Our finding that the LSr-LH pathway was Fos-activated during cocaine $\mathrm{CPP}$, and that inactivation of LSr reduced Fos specifically in LH orexin neurons during CPP test, indicates that a direct projection may be responsible for the disconnection results. However, we cannot rule out the possibility of an intermediate connection between LSr and LH orexin neurons.

\section{LS connections with LH orexin neurons: Role in cocaine preference}

We verified that injections of orexin A antisense into LH selectively attenuated orexin expression in $\mathrm{LH}$, but not in PFA/DMH areas, indicating that the results we obtained were a result of interrupting LS afferents to orexin neurons specifically in $\mathrm{LH}$. $\mathrm{MCH}$ is localized in non-orexin $\mathrm{LH}$ neurons and has been reported to be involved in cocaine seeking (Chung et al., 2009). We found that injections of orexin antisense did not affect $\mathrm{MCH}$ cell counts, indicating that the behavioral results did not involve $\mathrm{MCH}$, but rather were selective for orexin. Finally, recovery of orexin expression in $\mathrm{LH}$ was observed $14 \mathrm{~d}$ postinjection indicating that orexin neurons were viable during behavioral testing.

Notably, dynorphin is expressed in all orexin neurons (Chou et al., 2001) and recent results suggest that dynorphin is important in stress-induced drug seeking behaviors (Wee and Koob, 2010). Thus, one might propose orexin antisense is somehow interfering with dynorphin expression leading to the reduction in preference. However, results by McLaughlin and colleagues show that the $\kappa$ opioid receptor antagonist norBNI does not block expression of cocaine preference in nonstressed animals (McLaughlin et al., 2003), indicating that the results obtained in the current studies are likely specific to orexin and not dynorphin.

\section{Lateral septum and contextual reward processing}

The LS has classically been divided into dorsal, intermediate and ventral subregions based on cytoarchitecture and neuroanatomical circuitry (Swanson and Cowan, 1979). Risold and Swanson (1997a,b) defined multiple subregions in LS based on neurotransmitter expression combined with numerous other neuroanatomical properties. In the current study, we targeted the rostral portion of the LS including the rostral dorsal lateral LS and the rostral aspect of the caudal dorsal LS as described by Risold and Swanson (1997a). Consistent with previous studies (Yoshida et al., 2006), we noted that LH received strong ipsilateral projections from the rostral and caudal regions of the LS; however, only rostral LS projections to $\mathrm{LH}$ were Fos-activated during cocaine preference. Accordingly, we found unilateral inactivation of LSr and knockdown of orexin in contralateral LH significantly attenuated cocaine preference suggesting that an influence of LSr on LH orexin neurons is necessary for cocaine preference.

Recently, Luo et al. (2011) identified a functional circuit from CA3 of dorsal hippocampus through an LS relay to VTA. They found that this circuit is necessary for contextual reinstatement of cocaine-seeking (Luo et al., 2011). Notably, the primary relay for this circuit is caudodorsal LS, in contrast to the more rostral LS identified here an important regulator of LH orexin neuron function. Based on the results of Luo et al. (2011) and our current data, we propose a dichotomy in LS areas and drug-seeking, where the LSr activates LH orexin neurons and the LSc excites VTA dopamine neurons during contextual drug-seeking behaviors. Additionally, LH orexin neurons project heavily to VTA (Harris et al., 2005; Borgland et al., 2006; Moorman and Aston-Jones, 2010) raising the possibility that LSr affects VTA activity via LH orexin neurons.

Both rostral and caudal LS have massive connections with the dorsal hippocampus (Risold and Swanson, 1996, 1997b) and have been implicated in spatial and contextual information processing (Rawlins and Olton, 1982; Fraser et al., 1991; Takamura et al., 2006; Calandreau et al., 2007). In addition, LS has strong connections with brain regions associated with reward and motivation (hypothalamus, amygdala, and VTA) (Risold and Swanson, 1997b), and is important in many behaviors associated with motivation (Olds and Milner, 1954; Prado-Alcala et al., 1984; Cazala et al., 1998). In the current study, we show that LSr afferents to LH orexin neurons are critical for the expression of cocaine preference, a behavior that relies on contextual information and reward processing (Bardo and Bevins, 2000; Cunningham et al., 2006). Based on these and previous results, we speculate that LS is an important relay between contextual and motivational processes. Once contextual information is processed in the lateral septum, expression of reward-related behaviors relies on output to other brain regions such as the lateral hypothalamus.

\section{References}

Bardo MT, Bevins RA (2000) Conditioned place preference: what does it add to our preclinical understanding of drug reward? Psychopharmacology (Berl) 153:31-43.

Borgland SL, Taha SA, Sarti F, Fields HL, Bonci A (2006) Orexin A in the VTA is critical for the induction of synaptic plasticity and behavioral sensitization to cocaine. Neuron 49:589-601.

Borgland SL, Chang SJ, Bowers MS, Thompson JL, Vittoz N, Floresco SB, Chou J, Chen BT, Bonci A (2009) Orexin A/hypocretin-1 selectively promotes motivation for positive reinforcers. J Neurosci 29:11215-11225.

Boutrel B, Kenny PJ, Specio SE, Martin-Fardon R, Markou A, Koob GF, de Lecea L (2005) Role for hypocretin in mediating stress-induced reinstatement of cocaine-seeking behavior. Proc Natl Acad Sci U S A 102:19168-19173.

Calandreau L, Jaffard R, Desmedt A (2007) Dissociated roles for the lateral 
and medial septum in elemental and contextual fear conditioning. Learn Mem 14:422-429.

Cazala P, Norena A, Le Merrer J, Galey D (1998) Differential involvement of the lateral and medial divisions of the septal area on spatial learning processes as revealed by intracranial self-administration of morphine in mice. Behav Brain Res 97:179-188.

Chemelli RM, Willie JT, Sinton CM, Elmquist JK, Scammell T, Lee C, Richardson JA, Williams SC, Xiong Y, Kisanuki Y, Fitch TE, Nakazato M, Hammer RE, Saper CB, Yanagisawa M (1999) Narcolepsy in orexin knockout mice: molecular genetics of sleep regulation. Cell 98:437-451.

Chen S, Yang M, Miselis RR, Aston-Jones G (1999) Characterization of transsynaptic tracing with central application of pseudorabies virus. Brain Res 838:171-183.

Chou TC, Lee CE, Lu J, Elmquist JK, Hara J, Willie JT, Beuckmann CT, Chemelli RM, Sakurai T, Yanagisawa M, Saper CB, Scammell TE (2001) Orexin (hypocretin) neurons contain dynorphin. J Neurosci 21:RC168(1-6).

Chung S, Hopf FW, Nagasaki H, Li CY, Belluzzi JD, Bonci A, Civelli O (2009) The melanin-concentrating hormone system modulates cocaine reward. Proc Natl Acad Sci U S A 106:6772-6777.

Cunningham CL, Patel P, Milner L (2006) Spatial location is critical for conditioning place preference with visual but not tactile stimuli. Behav Neurosci 120:1115-1132.

Delfs JM, Zhu Y, Druhan JP, Aston-Jones GS (1998) Origin of noradrenergic afferents to the shell subregion of the nucleus accumbens: anterograde and retrograde tract-tracing studies in the rat. Brain Res 806:127-140.

Elias CF, Saper CB, Maratos-Flier E, Tritos NA, Lee C, Kelly J, Tatro JB, Hoffman GE, Ollmann MM, Barsh GS, Sakurai T, Yanagisawa M, Elmquist JK (1998) Chemically defined projections linking the mediobasal hypothalamus and the lateral hypothalamic area. J Comp Neurol 402:442-459.

Fraser KA, Poucet B, Partlow G, Herrmann T (1991) Role of the medial and lateral septum in a variable goal spatial problem solving task. Physiol Behav 50:739-744.

Hamlin AS, Clemens KJ, McNally GP (2008) Renewal of extinguished cocaine-seeking. Neuroscience 151:659-670.

Harris GC, Aston-Jones G (2003) Critical role for ventral tegmental glutamate in preference for a cocaine-conditioned environment. Neuropsychopharmacology 28:73-76.

Harris GC, Aston-Jones G (2006) Arousal and reward: a dichotomy in orexin function. Trends Neurosci 29:571-577.

Harris GC, Wimmer M, Aston-Jones G (2005) A role for lateral hypothalamic orexin neurons in reward seeking. Nature 437:556-559.

Harris GC, Wimmer M, Randall-Thompson JF, Aston-Jones G (2007) Lateral hypothalamic orexin neurons are critically involved in learning to associate an environment with morphine reward. Behav Brain Res 183:43-51.

Hutcheson DM, Quarta D, Halbout B, Rigal A, Valerio E, Heidbreder C (2011) Orexin-1 receptor antagonist SB-334867 reduces the acquisition and expression of cocaine-conditioned reinforcement and the expression of amphetamine-conditioned reward. Behav Pharmacol 22:173-181.

Lawrence AJ, Cowen MS, Yang HJ, Chen F, Oldfield B (2006) The orexin system regulates alcohol-seeking in rats. Br J Pharmacol 148:752-759.

Lin L, Faraco J, Li R, Kadotani H, Rogers W, Lin X, Qiu X, de Jong PJ, Nishino S, Mignot E (1999) The sleep disorder canine narcolepsy is caused by a mutation in the hypocretin (orexin) receptor 2 gene. Cell 98:365-376.

Luo AH, Tahsili-Fahadan P, Wise RA, Lupica CR, Aston-Jones G (2011) Linking context with reward: a functional circuit from CA3 of hippocampus to ventral tegmental area. Science 333:353-357.

Marchant NJ, Hamlin AS, McNally GP (2009) Lateral hypothalamus is required for context-induced reinstatement of extinguished reward seeking. J Neurosci 29:1331-1342.

Marcus JN, Aschkenasi CJ, Lee CE, Chemelli RM, Saper CB, Yanagisawa M, Elmquist JK (2001) Differential expression of orexin receptors 1 and 2 in the rat brain. J Comp Neurol 435:6-25.

McLaughlin JP, Marton-Popovici M, Chavkin C (2003) Kappa opioid receptor antagonism and prodynorphin gene disruption block stressinduced behavioral responses. J Neurosci 23:5674-5683.

Millan EZ, Furlong TM, McNally GP (2010) Accumbens shell-hypothalamus interactions mediate extinction of alcohol seeking. J Neurosci 30:4626-4635.

Moorman DE, Aston-Jones G (2009) Orexin-1 receptor antagonism decreases ethanol consumption and preference selectively in high-ethanolpreferring Sprague-Dawley rats. Alcohol 43:379-386.
Moorman DE, Aston-Jones G (2010) Orexin/hypocretin modulates response of ventral tegmental dopamine neurons to prefrontal activation: diurnal influences. J Neurosci 30:15585-15599.

Nishino S, Ripley B, Overeem S, Lammers GJ, Mignot E (2000) Hypocretin (orexin) deficiency in human narcolepsy. Lancet 355:39-40.

Olds J, Milner P (1954) Positive reinforcement produced by electrical stimulation of septal area and other regions of rat brain. J Comp Physiol Psychol 47:419-427.

Pasumarthi RK, Fadel J (2008) Activation of orexin/hypocretin projections to basal forebrain and paraventricular thalamus by acute nicotine. Brain Res Bull 77:367-373.

Paxinos G, Watson C (1998) The rat brain in stereotaxic coordinates, Ed 4. San Diego: Academic.

Peyron C, Tighe DK, van den Pol AN, de Lecea L, Heller HC, Sutcliffe JG, Kilduff TS (1998) Neurons containing hypocretin (orexin) project to multiple neuronal systems. J Neurosci 18:9996-10015.

Prado-Alcala R, Streather A, Wise RA (1984) Brain stimulation reward and dopamine terminal fields. II. Septal and cortical projections. Brain Res 301:209-219.

Rawlins JN, Olton DS (1982) The septo-hippocampal system and cognitive mapping. Behav Brain Res 5:331-358.

Reissner KJ, Sartor GC, Vazey EM, Dunn TE, Aston-Jones G, Kalivas PW (2012) Use of vivo-morpholinos for control of protein expression in adult rat brain. J Neurosci Methods 203:354-360.

Risold PY, Swanson LW (1996) Structural evidence for functional domains in the rat hippocampus. Science 272:1484-1486.

Risold PY, Swanson LW (1997a) Chemoarchitecture of the rat lateral septal nucleus. Brain Res Brain Res Rev 24:91-113.

Risold PY, Swanson LW (1997b) Connections of the rat lateral septal complex. Brain Res Brain Res Rev 24:115-195.

Sakurai T, Amemiya A, Ishii M, Matsuzaki I, Chemelli RM, Tanaka H, Williams SC, Richardson JA, Kozlowski GP, Wilson S, Arch JR, Buckingham RE, Haynes AC, Carr SA, Annan RS, McNulty DE, Liu WS, Terrett JA, Elshourbagy NA, Bergsma DJ, Yanagisawa M (1998) Orexins and orexin receptors: a family of hypothalamic neuropeptides and G proteincoupled receptors that regulate feeding behavior. Cell 92:573-585.

Sakurai T, Nagata R, Yamanaka A, Kawamura H, Tsujino N, Muraki Y, Kageyama H, Kunita S, Takahashi S, Goto K, Koyama Y, Shioda S, Yanagisawa M (2005) Input of orexin/hypocretin neurons revealed by a genetically encoded tracer in mice. Neuron 46:297-308.

Sharf R, Guarnieri DJ, Taylor JR, DiLeone RJ (2010) Orexin mediates morphine place preference, but not morphine-induced hyperactivity or sensitization. Brain Res 1317:24-32.

Shoji S, Simms D, McDaniel WC, Gallagher JP (1997) Chronic cocaine enhances gamma-aminobutyric acid and glutamate release by altering presynaptic and not postsynaptic gamma-aminobutyric acidB receptors within the rat dorsolateral septal nucleus. J Pharmacol Exp Ther 280:129-137.

Shoji S, Simms D, Yamada K, Gallagher JP (1998) Cocaine administered in vitro to brain slices from rats treated with cocaine chronically in vivo results in a gamma-aminobutyric acid receptor-mediated hyperpolarization recorded from the dorsolateral septum. J Pharmacol Exp Ther 286:509-518.

Smith RJ, See RE, Aston-Jones G (2009) Orexin/hypocretin signaling at the orexin 1 receptor regulates cue-elicited cocaine-seeking. Eur J Neurosci 30:493-503.

Smith RJ, Tahsili-Fahadan P, Aston-Jones G (2010) Orexin/hypocretin is necessary for context-driven cocaine-seeking. Neuropharmacology 58:179-184.

Sutcliffe JG, de Lecea L (2002) The hypocretins: setting the arousal threshold. Nat Rev Neurosci 3:339-349.

Swanson LW, Cowan WM (1979) The connections of the septal region in the rat. J Comp Neurol 186:621-655.

Takamura Y, Tamura R, Zhou TL, Kobayashi T, Tran AH, Eifuku S, Ono T (2006) Spatial firing properties of lateral septal neurons. Hippocampus $16: 635-644$.

Wee S, Koob GF (2010) The role of the dynorphin-kappa opioid system in the reinforcing effects of drugs of abuse. Psychopharmacology (Berl) 210:121-135.

Yoshida K, McCormack S, Espana RA, Crocker A, Scammell TE (2006) Afferents to the orexin neurons of the rat brain. J Comp Neurol 49:845-861. 